\title{
ARTICULAÇÃO ENTRE ENSINO, PESQUISA E EXTENSÃO: LIMITES E POSSIBILIDADES DE UMA EXPERIÊNCIA DE TRABALHO JUNTO À COMUNIDADE
}

\author{
Tatiana Noronha de Souza ${ }^{1}$
}

\begin{abstract}
RESUMO: Este artigo tem como objetivo relatar a experiência de um projeto de extensão universitária no interior do Estado de São Paulo, bem como o desafio da integração entre ensino, pesquisa e extensão. Este projeto é financiado pela PróReitoria de Extensão Universitária da Universidade Estadual Paulista Júlio de Mesquita Filho. Tem como objetivo principal desenvolver atividades relacionadas à alfabetização em língua portuguesa e alfabetização digital, voltadas para adultos e crianças. Temos trabalhado com três grupos distintos: (1) adultos que trabalham em uma cooperativa de catadores, em um aterro sanitário, (2) adultos portadores do vírus HIV e (3) apoio acadêmico voltado às crianças moradoras de um assentamento rural. Temos notado avanços no desenvolvimento intelectual dos diferentes grupos e, ao mesmo tempo, temos enfrentado muitas dificuldades para o desenvolvimento das atividades, devido às difíceis condições de vida dos participantes, que influenciam a adesão ao projeto. Conclui-se que o desenvolvimento de projetos junto à comunidades muito pobres é um desafio para a universidade, especialmente ao responder a uma demanda da comunidade, e não a necessidade da universidade.
\end{abstract}

Palavras-chave: Extensão universitária; Educação não-formal; Exclusão social.

ABSTRACT: This article aims to report the experience of one extension project, at São Paulo State, and the challenge of integration between teaching, research and extension. This project is sponsored by Pró-Reitoria de Extensão Universitária, da Universidade Estadual Paulista Júlio de Mesquita Filho. The main purpose of this project is to develop activities related to the literacy of the portuguese language and digital literacy applied to adults and children. We have worked with three different groups: (1) adults who work as waste pickers for a cooperative at sanitary lanfill; (2) adults who are HIV patients and (3) scholar support for a young children, in the rural settlements. We have noted advances in the field of intellectual development groups, and at the same time, we have been facing many difficulties to developed the activities due to very poor condition in which the participants life, related to take part into the project. It is concluded that the development of projects at poorer communities is a challenge for the university, especially when answering a demand from the community, and not the need of the university.

Keywords: Science outreach; Non-formal education; Social exclusion.

\section{INTRODUÇÃO}

Nos últimos anos os projetos de extensão universitária têm enfrentado grandes desafios, especialmente em função da lógica da produtividade que se estabeleceu na universidade brasileira. Assim como as atividades ligadas ao ensino de graduação, a extensão tem valor reduzido frente às atividades de

\footnotetext{
1 Docente do curso de Licenciatura em Ciências Biológicas da Faculdade de Ciências Agrárias e Veterinárias de Jaboticabal - UNESP. Doutorado em Psicologia pela USP.
} 
pesquisa, além de possuírem menos recursos. Diante disso, algumas universidades têm procurado articular as atividades de extensão e pesquisa, para que o dados de atividades de extensão possam ser utilizados como fonte de pesquisa, e divulgados em revistas científicas.

Por outro lado, autores como Martins (2008) defendem a indissociabilidade entre ensino, pesquisa e extensão na busca da excelência da formação profissional, realizada por meio do conhecimento a respeito do campo, e da produção do conhecimento. Esse modelo abrange tanto as dimensões ético-políticas quanto as didático-pedagógicas, que visam a construção de um sujeito práxico, integrado nos três grandes campos que constroem sua história: do trabalho, da sociabilidade e da cultura simbólica (SEVERINO, 2002).

Esta organicidade pressupõe a formação superior como síntese de três grandes processos, quais sejam: processos de transmissão e apropriação do saber historicamente acumulado, a pressupor o ensino; processos de construção do saber, a pressupor a pesquisa e os processos de objetivação ou materialização desses conhecimentos, a pressupor a intervenção sobre a realidade e que, por sua fez, retornam numa dinâmica de retro-alimentação do ensino e da pesquisa (MARTINS, 2008, p. 75).

Assim como apontado pela autora, trata-se de considerar essa indissociabilidade como fundamento metodológico do ensino superior, em defesa de uma universidade pública e qualidade, comprometida com o luta contra as desigualdades sociais, promovendo uma aproximação mais orgânica da universidade com a comunidade.

Pode-se dizer que identificamos duas diferentes correntes que defendem a indissociabilidade do ensino, da pesquisa e da extensão, sendo que a primeira insere-se dentro da lógica produtivista, e a segunda defende um campo de desenvolvimento profissional de qualidade, associado à intervenção da realidade, com vista à diminuição das desigualdades.

No presente texto defendemos que a educação tem como objetivo o desenvolvimento pleno das capacidades ontológicas dos sujeitos. Dentre elas, a capacidade de realização de uma leitura da realidade, análise e posterior planejamento de ações, com uma finalidade concreta de transformação de uma 
determinada realidade. Trata-se de um espaço de construção de subjetividade, que tem a práxis como fio condutor do trabalho. Práxis como exercício radical de analisar a realidade, com objetivo de transformá-la, levando em conta o contexto de injustiças e desigualdades sociais em que estamos imersos (FREIRE, 2003). Uma práxis que permita que essa ação sobre a realidade forneça subsídios para a construção da própria subjetividade.

Nesse sentido, o projeto de extensão que aqui será apresentado, tem como foco o trabalho com populações excluídas, ou em processos de exclusão do universo escolar, vítimas da desigualdade social imposta em nosso país. Um sistema que nega a possibilidade da formação educacional de qualidade, e a apropriação de instrumentos da cultura, produzidos pelo conhecimento historicamente acumulado. A história escolar mostra que são sujeitos que estão, ou serão, relegados a um espaço que priva de um desenvolvimento intelectual crítico e autônomo, submetendo-os a uma lógica que os leva ao rompimento do trabalho intelectual e manual, e que dificulta a superação dessa condição.

Ao refletirmos sobre o papel da escola na vida dessas pessoas, retomamos Bourdieu (1993) ao tratar da escola conservadora, que lança mão de mecanismos de reprodução de uma condição social historicamente construída, que vem sendo mantida por meio das relações entre dominantes e dominados numa sociedade de classes. Trata-se de uma educação que homogeneíza e marca a formação do educando ao negar o acesso ao conhecimento historicamente acumulado e o desenvolvimento do pensamento crítico.

Bourdieu aponta que há um interesse na manutenção da estrutura social vigente - econômica, social e política - que faz com que os grupos hegemônicos não compartilhem o mesmo espaço educacional daqueles que são ou serão dominados. Por essa razão observamos que o acesso aos bancos escolares e a determinados tipos de escola está submetido à lógica perversa de uma sociedade injusta e desigual. Essa lógica imprime nos diferentes grupos formas de pensar em conformidade com o espaço social que cada um deles deve ocupa, que se revelam nas suas práticas sociais cotidianas. 
Preocupados com as condições de exclusão social de determinados grupos, professores da Universidade Estadual Paulista Júlio de Mesquita Filho, Campus de Jaboticabal, propuseram um projeto de extensão no campo da alfabetização, com o intuito de fornecer aos educandos instrumentos para a busca da superação das condições de exclusão social. Trata-se de um projeto que está em curso desde 2006, e enfrenta vários desafios junto aos alunos de graduação e também junto à comunidade atendida.

Assim, o objetivo do presente artigo é realizar um relato deste trabalho de extensão e dos diferentes desafios que se colocam para a sua realização, tais como a falta de articulação clara entre ensino, pesquisa e extensão, e as dificuldades de atendimento às demandas da comunidade quando se trata de grupos em condição de exclusão social.

\section{CONTEXTO DE DESENVOLVIMENTO DO PROJETO E SUAS FRENTES DE ATUAÇÃO}

O projeto Alfabetização e Inclusão Digital para a Cidadania e Autogestão nasceu em 2006, fruto de uma necessidade observada no projeto de extensão universitária intitulado Projeto Suporte, que desde o ano de 2003 tem como objetivo apoiar grupos sociais organizados, para geração de trabalho e renda, visando o desenvolvimento da autogestão e autossuficiência. Coordenado por duas docentes, conta com a participação de alunos do Curso de Administração, da Faculdade de Ciências Agrárias e Veterinárias e Jaboticabal, financiado pela Pró-Reitoria de Extensão Universitária da Universidade Estadual Paulista Júlio de Mesquita Filho - UNESP.

No decorrer do trabalho junto às ONGs, verificou-se a necessidade da realização de um trabalho de alfabetização em língua portuguesa e inclusão digital como forma de apoiar o desenvolvimento da cidadania, autonomia e auto-suficiência do grupo. Além disso, pretendia-se possibilitar uma participação mais ativa e consciente nos processos de tomada de decisão, por meio da compreensão de que eram sujeitos da própria história, capazes de se autogerir.

No ano de 2005 o Projeto Suporte iniciou suas atividades junto a um grupo de catadores e separadores de lixo, que trabalhavam no aterro sanitário 
da cidade de Jaboticabal, momento em que a cooperativa já estava em situação ilegal. É necessário destacar que a história do relacionamento dessa cooperativa com o poder público municipal é permeada por avanços e retrocessos. Em 2001 foi instituída a Política Pública Municipal em Economia Solidária, que incluía a criação de uma cooperativa de triagem de lixo do município. De acordo com os documentos oficiais, tinha como objetivo oferecer trabalho para catadores e separadores de lixo do município. Este processo de organização da cooperativa foi realizado unilateralmente pelo poder municipal, que reuniu os trabalhadores e os organizou em um grupo que veio a se constituir como cooperativa, com termos e compromisso elaborados exclusivamente por técnicos municipais (BRANCALEONI, BORGES, 2010). Observa-se, assim, a realização de um processo antidemocrático, que não contou com a participação dos trabalhadores nos processos de decisão e planejamento das atividades, o que fez que não houvesse a apropriação dos cooperados, no sentido cooperativista, sendo reproduzido o modelo de trabalho alienante e autoritário, tal como se observa nas fábricas. Brancaleoni e Borges (2010) apontam que essa relação autoritária também pôde ser observada na dinâmica interna da cooperativa, no momento da construção do regimento interno pelo grupo, tais como: advertências e suspensões para os comportamentos tidos como inadequados, assim como para as conversas paralelas durante o trabalho na esteira. Verifica-se, assim, que a cooperativa funcionou enquanto um mecanismo de precarização das relações trabalhistas, bem como da permanência de uma política assistencialista, refletida na falta de estímulo à autogestão.

Ao longo do primeiro ano de trabalho junto aos catadores observou-se a necessidade de ações voltadas para a alfabetização, como apoio às atividades para o desenvolvimento de um grupo autogerido. Essa necessidade foi observada por aqueles que desenvolviam o projeto, além de ter surgido como uma demanda do grupo de trabalhadores. Desse modo, em 2006 o projeto de Alfabetização e Inclusão Digital foi aprovado pela Pró-Reitoria de Extensão da UNESP, com o objetivo inicial realizar atividades de alfabetização em língua portuguesa, e inclusão digital, junto a adultos de grupos e ONGs.

Até o ano de 2011 o projeto passou por duas diferentes coordenações e, desde então, está sendo conduzido pela mesma coordenadora. Por essa 
razão, destacamos que as informações aqui apresentadas referem-se àquelas colhidas a partir de 2011.

\section{FRENTES DE ATUAÇÃO E REFERENCIAIS TEÓRICOS UTILIZADOS}

Como dito anteriormente, a nova coordenação do projeto, iniciada em 2011, deu continuidade às atividades de Alfabetização em Língua Portuguesa, junto aos trabalhadores do Aterro Sanitário. Naquele mesmo ano observamos a necessidade de incluir atividades de Alfabetização Matemática, tendo em vista a importância da apropriação dos saberes matemáticos para 0 desenvolvimento da autonomia daqueles trabalhadores.

Para as atividades de alfabetização realizamos a leitura de materiais que devem fundamentar as práticas, tais como, A concepção "bancária" da educação como instrumento da opressão, seus pressupostos, sua crítica (FREIRE, 2003), O que é o método Paulo Freire (BRANDÃO, 1981) e Pedagogia da autonomia (FREIRE, 2002). Dessa literatura destacamos alguns princípios essenciais, tais como:

(1) respeito profundo à condição do educando;

(2) educador é também aquele que aprende;

(3) o educando não serve de depósito de informações, mas participante da construção do seu conhecimento;

(4) alfabetizar é também trabalhar a leitura do mundo, com vistas ao desenvolvimento do pensamento crítico;

(5) levantar o conhecimento de mundo dos alunos, e articulá-lo criticamente aos novos conhecimentos;

(6) a relação educador-educando é horizontal e não vertical;

(7) a educação é um ato político, jamais neutro.

(8) o material didático é construído a partir do diálogo entre o educador e o educando.

Essa lista de princípios rege o planejamento e desenvolvimento das atividades do projeto, sendo que a construção de material didático talvez seja um dos maiores desafios junto ao grupo. Isso porque os observamos a 
dificuldade de coletar e analisar os saberes apresentados pelos educandos, e pesquisarmos os melhores meios para o desenvolvimento do trabalho. Trata-se de uma busca contínua para aprender a compreender os processos de aprendizagem tanto dos educadores como dos educandos, com o intuito de criar novas formas de construir conhecimentos diversos.

No caso da Alfabetização Matemática compartilhamos a compreensão de Danyluk (2002) ao tratar como uma ação de ler e escrever matemática, que permita a compreensão e interpretação de conteúdos básicos, além de saber se expressar por meio dessa linguagem. Por essa razão, procuramos trabalhar a matemática de forma contextualizada, e não mecânica. Além da resolução de problemas matemáticos, o educando deve compreender a implicação do resultado, dentro de um determinado contexto. Esses princípios nortearam, e ainda norteiam nossas ações, e são sistematicamente retomados nas reuniões de supervisão.

Nossas visitas semanais ao aterro sanitário ocorreram de março de 2011, a junho de 2012. Os encontros eram realizados em uma casa, dentro do aterro, na qual os trabalhadores realizavam suas refeições, descansavam e utilizavam o banheiro. Havia duas salas disponíveis, nas quais trabalhávamos com três diferentes grupos: (1) analfabetos plenos; (2) analfabetos funcionais; (3) grupo com foco na matemática.

Os analfabetos plenos eram três pessoas que, por meio de um diagnóstico inicial, verificou-se que não sabiam ler e escrever, nem identificavam corretamente as letras; dois deles não conseguiam escrever o próprio nome. Eram homens entre 40 a 60 anos, com histórico de saída da escola nas séries iniciais, para realizarem o trabalho no corte de cana. Esse processo de exclusão podia ser observado, inclusive, pela dificuldade de se expressarem oralmente. Neste caso, os alunos responsáveis por esse grupo procuravam levantar, frequentemente, o universo vocabular dos educandos, construir meios para aquisição e desenvolvimento da linguagem oral e escrita, utilizando imagens, bem como outros recursos de apoio.

Os analfabetos funcionais, com oito pessoas em média, eram aqueles que escreviam mal, muitas vezes não entendiam o que tinham escrito, e possuíam muita dificuldade de leitura. As atividades envolviam leitura e discussão de reportagens que tratavam de questões do cotidiano do grupo, 
produção de textos, atividades de matemática, geografia, ciências e saúde. A mudança de atividade ou tema era negociada entre o grupo.

O grupo com foco na matemática, que contava com cerca de três participantes, já possuía maior domínio sobre a escrita, além da leitura e compreensão de textos, e se mostrou interessado em aprofundar o pouco conhecimento que tinham sobre matemática.

A decisão de separação dos grupos se deu em razão dos trabalhadores apresentarem diferentes demandas, além disso, os alunos que participavam o trabalho também disseram preferir desenvolver atividades com pequenos grupos e mais homogêneos. Apesar de considerarmos a importância da aprendizagem coletiva, em que ocorre a troca de saberes entre os participantes, consideramos que não tínhamos uma experiência que pudesse subsidiar uma ação de tamanha complexidade, assim, organizávamos momentos de conversa coletiva, e para o desenvolvimento de atividades individuais. O número de participantes variou ao longo dos meses, especialmente no grupo de analfabetos funcionais, tendo em vista a alta rotatividade de trabalhadores no aterro. Isso porque alguns conseguiram empregos que ofereciam melhores condições de salubridade.

Nos três grupos foram observados avanços no campo da alfabetização, com reflexo claro na autoestima dos participantes. Isso pôde ser observado ao longo do trabalho, por meio dos depoimentos espontâneos dos participantes. É interessante destacar as características dos grupos com maior assiduidade, que não interrompiam o trabalho no aterro: os analfabetos plenos e o grupo da matemática. Os analfabetos plenos possuíam uma grande dificuldade de aprendizagem, limitações no campo da expressão oral e, consequentemente, pouca chance de conseguirem trabalhos melhores. Os educandos do grupo da matemática eram aqueles que mais dominavam a língua escrita e procuravam aprender melhor matemática e, não por coincidência, eram os que acabavam por centralizar as atividades de gestão da associação.

A partir do ano de 2012, pioraram as condições de trabalho no aterro, e os trabalhadores passaram a contar muito pouco com a ajuda do poder público. Um dos aspectos que mais influenciou nosso projeto foi a diminuição do tempo de trabalho no aterro, o que fez com que os educandos parassem de frequentar as aulas. Isso porque duas horas de aula significavam duas horas a 
menos de separação de resíduos sólidos, consequentemente, menos ganho. Considerando a condição de miséria do grupo, nossos argumentos relativos à importância da alfabetização, para a promoção de autonomia e independência pouco impactava os trabalhadores, pois, em primeiro lugar, vinha a necessidade de sobrevivência. Assim, o trabalho foi interrompido em meados de 2012.

Naquele momento outro grupo vinha se mostrando interessado no trabalho desenvolvido pelo grupo da Alfabetização. Eram pacientes do Centro de Referência em Infectologia (Ambulatório de DST/Aids), participantes de um grupo de apoio coordenado por um psicólogo, que tinha como objetivo reinserir aqueles pacientes que estavam desempregados, no mercado de trabalho, ou organizá-los em grupos para geração de renda. Inicialmente vários pacientes se mostraram interessados em participar de atividades ligadas à alfabetização digital, pois muitos não sabiam ligar o computador, e outros não sabiam utilizar a internet e editores de textos. Assim, iniciamos o trabalho no segundo semestre de 2012, com um grupo de quatro pacientes, pois era o número de notebooks disponíveis para o projeto.

Os encontros eram realizados uma vez por semana, por um período de duas horas, no período da tarde, em uma sala do próprio centro de infectologia. Nesses encontros eram trabalhados aspectos relativos à Alfabetização digital, procurando atender também os interesses dos alunos, pacientes do centro. Um exemplo dessa tentativa de articulação foi o trabalho com uma aluna, que tinha interesse em aprender a trabalhar com o Exel. Ao levantarmos informações sobre seu contexto de vida, verificamos que ela ajudava administrar o bar de seu companheiro. Assim, decidiu-se pela montagem de lista de compras, e controle de entrada e saída de produtos. Neste caso, além de aprender a lidar com o programa, trabalha-se com Língua Portuguesa e Matemática, simultaneamente. Junto a este grupo também realizava-se o trabalho com pequenos filmes, reportagens e jornal, poesias, e qualquer outro material que pudesse dar suporte para uma discussão e reflexão sobre as condições de vida dos participantes, e os desafios a serem enfrentados.

Essa frente de trabalho também apresentou dificuldades em função da alta rotatividade dos alunos. Os motivos foram listados foram: adoecimento em função das doenças que desenvolviam, reação à medicação, depressão, falta 
de recursos para se deslocarem para o Centro de Infectologia, inadequação do horário proposto pelo nosso grupo, no caso de pacientes que conseguiam trabalho. Procuramos transferir os encontros para a sala de informática da UNESP, porém, continuaram os mesmos problemas relativos à frequencia e abandono das atividades.

Destaca-se a permanência de uma aluna, ao longo do ano, sem interrupção. Ela apresentou grandes avanços na aprendizagem do uso do computador, e passou a utilizá-lo com total autonomia. Os demais participavam de poucos encontros, e não se mantinham frequentes. Esse fato nos traz várias indagações, especialmente por ter sido uma demanda apresentada pela comunidade. Inicialmente havia um interesse explícito do grupo, o que nos levava a crer que esses pacientes viam sentido nas atividades que seriam realizadas, e a importância da alfabetização digital para a sua formação, que possibilitaria, inclusive, ganhos futuros. Mesmo assim, não houve adesão o suficiente para mantermos essa frente, tendo sido encerrada após uma no, em agosto de 2013.

Num momento anterior, junho de 2013, a coordenação do projeto foi procurada por um técnico do Instituto de Terras do Estado de São PauloITESP, que buscava parceria para o desenvolvimento de atividades de reforço escolar, junto a crianças moradoras de um assentamento rural, no interior de São Paulo. Trata-se de um assentamento pequeno, que possui 60 famílias, conhecido como Associação dos produtores de agricultura familiar do Córrego Rico - A terra rica. Nele há em torno de 30 crianças e jovens, em idade escolar. Inicialmente realizamos um encontro com a líder da comunidade, juntamente com outras mulheres que participavam da assembleia semanal. Naquele momento apresentamos nosso trabalho e levantamos as demandas daquela comunidade, com relação às crianças. As mães se mostraram preocupadas porque entendiam que as crianças não estavam conseguindo acompanhar as atividades realizadas na escola, pois pareciam que eram deixadas de lado. Na avaliação delas, o transporte para a escola, se constitui num entrave para o bom andamento escolar, pois ele não ocorre em períodos de chuva, e as crianças acordam de madrugada para serem levadas à escola, o que diminui o rendimento em função de dormirem na sala de aula. 
Diante dessas informações, marcamos encontros semanais de duas horas, no período da tarde, no barracão do assentamento. No início, as crianças (cerca de sete) levavam o material escolar nos encontros. Isso se deu porque era necessário saber quais eram as atividades que vinham sendo desenvolvidas na escola, e quais eram as dificuldades apresentadas pelas crianças. Verificou-se que, no caso das crianças das séries iniciais, havia um hiato entre as atividades propostas no livro didático, e o conhecimento que as crianças possuíam. Essas crianças ainda estavam num estágio inicial de alfabetização, não possuíam a escrita alfabética, e o livro didático apresentava atividades para alunos já alfabetizados. Esse fato fez com que o grupo mudasse a estratégia de trabalho, abandonando temporariamente as atividades ligadas ao livro didático, para desenvolver atividades de alfabetização. Essas atividades são compostas por desenhos, produção de livros, construção de histórias, recorte e colagem e até projeção de filmes, e promovem um grande envolvimento por parte das crianças, que possuem poucas oportunidades para atividades de desenho e criação.

Observou-se um avanço nas atividades ligadas ao desenvolvimento da língua escrita, muito provavelmente em função do trabalho personalizado, que envolve atividades que fazem sentido para as crianças. Esses avanços podem ser constatados nas produções das crianças, e no envolvimento e frequência das mesmas, nas atividades desenvolvidas pelo projeto. Podemos dizer que nessa frente de trabalho o único empecilho que temos encontrado é a frequência das crianças que moram distantes do barracão. Notamos que as ausências nos encontros se dão em função das algumas crianças desistirem de caminhar pela estrada de terra, por mais de 20 minutos, embaixo do sol forte.

As descrições do trabalho realizado nessas diferentes frentes nos mostram que fatores externos ao projeto impedem, muitas vezes, a participação dos sujeitos nas atividades. São variáveis que, na maioria das vezes, fogem ao controle daqueles que desenvolvem o trabalho, e que dificilmente podem ser sanadas. Desse modo, atualmente o projeto encontrase em momento de avaliação, e procurará centrar os esforços nas atividades junto às crianças do assentamento, pois, apesar da dificuldade de acesso por algumas crianças, notamos um alto grau de envolvimento nas atividades, 
verificado por meio dos depoimentos positivos fornecidos pelas crianças, e pelas mães.

\section{A PARTICIPAÇÃO DOS ALUNOS DE GRADUAÇÃO NAS DIFERENTES FRENTES DO PROJETO}

No início o projeto foi desenvolvido por alunos do curso de Administração e, paulatinamente, passou a contar com maior participação dos alunos do curso de ciências biológicas, da mesma faculdade. Atualmente não conta com alunos do curso de Administração, muito provavelmente em função da distância da área de atuação do projeto, com relação à área de formação na graduação. Nesse sentido, observamos ao longo do tempo uma grande rotatividade de alunos no projeto, sendo observada certa estabilidade somente quando estão recebendo bolsa.

Os alunos do curso de Ciências Biológicas parecem mais envolvidos nas atividades, apesar das dificuldades apresentadas para a construção e acompanhamento das atividades de alfabetização. Nas reuniões de supervisão pode-se observar uma preocupação desses alunos com a qualidade de vida dos educandos do projeto, o que extrapola a preocupação com a aprendizagem da técnica, e se apresenta como compromisso deles frente à comunidade. Atualmente o projeto conta com a participação de seis alunos de graduação, sendo dois bolsistas.

\section{CONSIDERAÇÕES FINAIS}

Um dos maiores desafios internos para o grupo foi e ainda é o que podemos chamar da distância entre a formação desenvolvida na graduação e posterior atuação profissional, daquela exigida no projeto de extensão. A princípio poderíamos dizer que atividades de alfabetização deveriam ser realizadas por alunos e alunas de cursos de Pedagogia, tendo em vista que são eles que passam por uma formação em alfabetização. Como não é o caso, cabe à coordenação realizar reuniões semanais com os alunos, para a discussão e supervisão das atividades, de forma a possibilitar alguma formação para a realização de atividades para alfabetização. 
Esse distanciamento da formação e atuação profissional, com as atividades desenvolvidas pelo projeto de extensão, se revela na falta de interesse, por parte de alguns alunos, na leitura de textos teóricos para dar suporte às atividades, na produção de registros de campo sobre os encontros e alta rotatividade no projeto. Com algumas exceções, o tempo de permanência dos alunos desde 2011 é de cerca de um ano. Em geral, a maior parte dos alunos deixa o projeto em função de atividades de iniciação científica com bolsa, ou estágios fora da universidade, dessa forma, trabalhamos sempre com uma média de quatro alunos.

Ademais, algumas outras questões também podem ser consideradas como problemáticas para o presente trabalho, tendo em vista às novas exigências da universidade, com relação à produção científica advinda da extensão, são elas: (1) falta de interesse dos alunos em irem a congressos que tenham como um dos temas a alfabetização; (2) o tema alfabetização não se constitui como área de pesquisa da docente coordenadora.

Diante desses desafios, nos colocamos a seguinte questão: Como atender a uma demanda da comunidade quando a universidade mais próxima não atua diretamente na área cuja demanda se encontra? O fato de não possuirmos uma relação direta com a pesquisa e ensino invalida as tentativas de responder às demandas expressas pela comunidade local?

Mesmo concordando com a importância da estreita relação entre ensino, pesquisa e extensão, não desconsideramos a possibilidade da realização de projetos que tenham como foco a busca do atendimento de uma demanda da comunidade. Como no caso do projeto em questão, a demanda atendida não é conteúdo de ensino e pesquisa daquela unidade universitária, entretanto, acreditamos que contribuições podem ser dadas quando o grupo se compromete em realizar os esforços necessários ao atendimento.

É importante destacar que a articulação entre ensino, pesquisa e extensão não garante que os trabalhos atendam a uma demanda real da comunidade, pois também possibilita a existência de projetos construídos unilateralmente pela universidade, para satisfação de índices que nada tem a ver com a promoção do desenvolvimento social. Neste caso, perpetua-se o modelo autoritário e assistencialista, em que a universidade parece saber do 
que a comunidade precisa, sem se preocupar em analisar qual o sentido do projeto para o público atendido.

Temos feito esforços para realizar uma articulação mais clara das atividades realizadas por este projeto, e a formação dos licenciandos em Ciências Biológicas. Acreditamos no processo de ensino-aprendizado como atividade em que educandos (os atendidos pelo projeto) e educadores (os alunos de graduação) aprendem e transformam seus conceitos e percepções de mundo. Verificamos a influência do projeto na formação pessoal dos graduandos, com a ampliação da visão de mundo acerca das desigualdades sociais, desenvolvimento de uma consciência social crítica sobre as políticas públicas, que ultrapassa os discursos meritocráticos do senso comum, que discriminam e excluem diferentes grupos sociais.

Ao retomarmos Martins (2008) e a necessária articulação junto ao ensino, pesquisa e extensão, verificamos que as condições de produção e desenvolvimento do projeto aqui em questão não permitem uma estreita articulação dessas três dimensões. Entretanto, não podemos deixar de dizer que observamos que permitimos aos nossos alunos o desenvolvimento de capacidades intelectuais que envolvem a pesquisa, a análise e a intervenção na realidade. Isso porque a coordenação procura oferecer apoio para a realização de assimilações cada vez mais aprofundadas sobre o objeto de intervenção, o rompimento com o pensamento cartesiano, e a necessária luta contra as injustiças sociais que marcam nossa sociedade.

\section{REFERÊNCIAS BIBLIOGRÁFICAS}

BRANCALEONI, Ana Paula Leivar; BORGES, Ana Claudia Giannini. Saúde e Segurança no trabalho em uma associação de reciclagem de Jaboticabal. In: I Seminário de Saúde do Trabalhador de Franca, 2010, Franca. Seminário de Saúde do Trabalhador de Franca, 2010.

BRANDÃO, Carlos Rodrigues. O que é o Método Paulo Freire. São Paulo: Brasiliense, 1981. (Col. Primeiros Passos, n. 38).

BOURDIEU, Pierre. Escritos de Educação. 14. Ed. Petrópolis, RJ: Vozes, 2013. 
DANYLUK, Ocsana. Alfabetização matemática: as primeiras manifestações da escrita infantil. Porto Alegre: Sulina: EDIUPF, 2002.

FREIRE, Paulo. Pedagogia do Oprimido. 35. Ed. São Paulo: Paz e Terra, 2003.

Pedagogia da Autonomia: saberes necessários à prática educativa. São Paulo: Paz e Terra, 2002.

MARTINS, Lígia Márcia. A indissociabilidade Ensino-Pesquisa-Extensão como um dos fundamentos metodológicos do Ensino Superior. In: PINHO, Sheila Zambello de (Org.). Oficinas de Estudos Pedagógicos: reflexões sobre a prática do Ensino Superior. São Paulo: Cultura Acadêmica; Editora UNESP, 2008. p. 102-115. V. 1.

SEVERINO, Antonio Joaquim. Competência técnica e sensibilidade éticopolítica: o desafio da formação de professores. Cadernos FEDEP, São Paulo n. 1, 2002, p. 10-23. 